\title{
El problema de las reclamaciones colectivas y el de la audiencia de la Corporación interesada tras el nuevo Reglamento económico-administrativo
}

\author{
por \\ JULIO VIZUETE GALLEGO \\ Licenciado en Derecho y en Ciencias Politicas \\ Secretario del Ayuntamiento de Calasparra
}

SUMario: I) El objeto de estudio.-II) Las reclamaciones económico-administrativas colectivas: A) Lo que el Reglamento de 1959 admite como reclamaciones económico-administrativas colectivas no son reclamaciones económico-administrativas: 1) Examen del Derecho positivo local; 2) Legislación del procedim:ento económico-administrativo; 3) aDe iure condendo».-B) Las reclamaciones económico-administrativas contra la aplicación y efectividad de exacciones locales pueden ser colectivas: 1) Examen del Derecho positivo; 2) aDe iure condendon.-III) La audiencia de la Corporación interesada: A) Examen del Derecho positivo.-B) $\alpha \mathrm{De}$ iure condendos.

\section{I) EL OBJETO DE ESTUdio}

La revisión del Reglamento de las reclamaciones económicoadministrativas venía ya autorizada por el artículo 11 de la Ley de 9 de mayo de 1950, que introdujo importantes modificaciones tanto en el Decreto orgánico de esta jurisdicción como en su Reglamento de procedimiento de 29 de julio de 1924 . Pero la promulgación "ex novo" fue ordenada por la tercera disposición final de la Ley de Procedimiento administrativo de 17 de julio de 1958, que establecía que por la Presidencia del Gobierno y 
el Ministerio de Hacienda se redactara y propusiera a la aprobación del Consejo de Ministros, en el plazo de un año, un nuevo Reglamento de estas reclamaciones, ajustado a las prescripciones de la nueva Ley básica del procedimiento administrativo, sin perjuicio de las especialidades que exigiera la peculiaridad de la materia.

Este imperativo se ha cumplido casi en el plazo fijado, puesto que el nuevo Reglamento tiene fecha de 26 de noviembre de 1959 . En conjunto, este ordenamiento nos parece altamente superior al de 1924, no sólo en cuanto a su ordenación sistemática (que sigue las directrices de la Ley básica, como se dice en su Exposición de motivos), sino también en cuanto a su contenido (depurado de materias ajenas al procedimiento que regula) y al rigor jurídico de su exposición.

En lo que sigue nos vamos a referir a dos importantes incidencias del nuevo Reglamento en aquella parte del procedimiento local a que afecta: las reclamaciones colectivas y la audiencia de la Corporación interesada. En la disposición final cuarta de la Ley de Procedimiento administrativo se faculta al Gobierno para revisar las disposiciones de procedimiento contenidas en la legislación local, para ajustarlas a ella, sin perjuicio de las especialidades que exija el procedimiento de las Corporaciones locales; no se ha hecho uso aún de esta facultad, para cuyo ejercicio no se señalaba plazo. Por ello, rigiendo plenamente el régimen local vigente, interesa resaltar algunos extremos del mismo, que están en contradicción con el establecido en el Reglamento de 26 de noviembre de 1959 , para esclarecer su aplicabilidad y para que sean tenidos en cuenta cuando se haga dicha revisión como especialidades del procedimiento local que conviene conservar (1).

(1) Las aludidas contradicciones no son sino una consecuencia más cel grave peligro para la claridad del ordenamiento jurídico que implica la disparidad de criterios que se siguen en cuanto se refiere a la legislación que atañe a las Entidades locales, pretendiendo unas veces codificar los preceptos que regulan las relaciones juridico-administrativas en que son parte los entes locales y siguiendo, otras, un criterio de codificación por materias; basculando entre estas opuestas directrices, se olvida con demasiada frecuencia que para la esfera local se han 
En lo que sigue se examinan, pues, las cuestiones apuntadas desde el punto de vista del Derecho positivo y señalando las directrices que se estima debe seguir al respecto la proyectada modificación del régimen local. Para ello, hemos prescindido de definiciones que pudieran prejuzgar las soluciones que se apuntan, y, dando por buenos los conceptos de reclamación económico-administrativa y acto reclamable que se inducen de los preceptos legales, hacemos la exégesis de éstos siguiendo su línea doctrinal.

Ha cumplido un año el Reglamento que nos ocupa, y estimamos examinar su influencia en el régimen loca:, tema interesante.

II) LAS RECLAMACIONES ECONÓMICO-ADMINISTRATIVAS COLECTIVAS

El artículo 727 de la Ley de Régimen local vigente, dice literalmente en cuanto ahora nos interesa: “1. Las reclamaciones sobre aplicación y efectividad de exacciones tendrán carácter económico-administrativo a los efectos del procedimiento, y podrán ser interpuestas colectivamente cuando afecten en forma y por motivos similares "varios contribuyentes".

El artículo 42 del nuevo Reglamento de las reclamaciones económico-administrativas dice en su número $2 .^{\circ}$ que éstas podrán ser colectivas: “2. ${ }^{\circ}$ Cuando se trate de varios interesados que ostenten el mismo derecho, hayan sido lesionados por un mismo acto administrativo o hagan uso de las mismas excepciones. Se entenderán comprendidas en este caso las reclamaciones sobre exacciones locales que se refieran a la modificación o nulidad de

\footnotetext{
establecido preceptos que resultan opuestos a los contenidos en disposiciones posteriores que regulan con carácter general materias aisladas. El problema ha s:do denunciado por autores prestigiosos, pero se ha hecho poco para remediarlo: Vid., por ejemplo, García DE ENTERRfa: Sobre utn texto refundido de la legislación contencioso-administrativa, en aRevista de Administración Públican número 6; del mismo autor: La primera derogación importante de la Ley de Régimen lucal, en Revista de Estudios de la VIda lLocal, núm. 6S; de GonzÁlez Pérez: El recurso contencioso-administrativo y el texto refundido de la I.ey de Régimen local, en Revista DE Estudios dE LA VIda Local, núm. 84, etc.
} 
las mismas, pero no a las que se entablen contra la procedencia de las cuotas impuestas, las cuales deberán ser individuales y entablarse por los propios interesados que se estimen agraviados o por sus legitimos representantes".

Por la simple lectura de ambos preceptos se aprecia la discrepancia que existe entre ellos. Con arregio a la legislación local, pueden formularse reclamaciones económico-administrativas colectivas contra las cuotas giradas por las exacciones locales; según el Reglamento de estas reclamaciones, no pueden interponerse éstas colectivamente contra las cuotas impuestas, y sólo sí cuando se pretenda la modificación o nulidad de la exacción de que se trate. Examinando esta evidente contradicción a la luz de la doctrina, del Derecho positivo y de la práctica, ha de llegarse a la conclusión de que el Reglamento de 1959 contiene en el artículo que nos ocupa un doble error: A) Lo que entiende y admite como reclamaciones económico-administrativas colectivas no son en recta técnica jurídica reclamaciones económico-administrativas; B) Las verdaderas reclamaciones económico-administrativas pueden ser siempre interpuestas colectivamente, contra lo que el Reglamento establece.

\section{A) Lo que el Reglamento de 1959 admite como reclamaciones económico-administrativas colectivas no son reclamaciones eco- nómico-administrativas}

El Reglamento de 1959 se ha limitado en su artículo 42 que nos ocupa, como en otras ocasiones, a copiar literalmente el correspondiente precepto (en este caso, el artículo 23) del derogado de 1924, y admiten uno y otro las reclamaciones colectivas "sobre exacciones locales que se refieran a la modificación o nulidad de las mismas". Es decir, dan el carácter de reclamaciones económico-administrativas a las que pretenden la anulación o la modificación de alguna exacción local.

Ahora bien, la anulación de una exacción local no es sino consecuencia de la declaración de la improcedencia de su imposición ; cuando en el "petitum" de un escrito de alegaciones se pretende 
del Tribunal que anule una exacción, lo que se impugna es la imposición de ésta, interesando del órgano decisor que deje sin efectos el acto administrativo que creó el tributo. Del mismo modo, cuando se pide a un Tribunal la modificación de una exacción, lo que se está atacando es la regulación u ordenación por la que se hace efectiva la figura fiscal de que se trata, es decir, la Ordenanza correspondiente. Por ello, cuando se habla de reclamaciones que se refieren a la nulidad o modificación de exacciones, debe entenderse que se trata de reclamaciones sobre la imposición de las mismas o sobre sus Ordenazas reguladoras, pretendiendo la anulación de aquélla o la modificación de éstas (2).

Establecida la evidente equivalencia de unas y otras expresiones, resalta la inadvertida incongruencia del Reglamento de 1959 , puesto que es a todas luces manifiesto que contra la imposición de exacciones locales (pretendiendo su nulidad) o contra las Ordenanzas reguladoras de las mismas (pretendiendo su modificación), no se admiten en el actual ordenamiento jurídico español las reclamaiciones económico-administrativas. Los referidos actos administrativos generales están sometidos a control gubernativo y jurisdiccional, pero entre la gama de acciones que se ofrecen para su impugnación no se cuentan las reclamaciones de tal naturaleza procesal; sólo a un lamentable afán de copia se puede atribuir el olvido en el Reglamento de 1959 de este inconcuso principio, cuya formulación vamos a ver en los apartados que siguen a través del Derecho local y de la legislación económico-administrativa.

1) Examen del Derecho positivo local.

Para llegar a la aplicación y efectividad de una exacción local es preciso pasar por cuatro momentos procedimentales, que le-

(2) Carece de relevancia para nuestro estudio el hecho de que el Tribunal se limite a la declaración de la nulidad o a la de la procedencia de la modificación, dejando para la ejecución de su fallo por la Corporación afectada la revocación de la imposición o la aprobación de la modificación falladas, con arreglo al artículo 116 del Reglamento. Tampoco obsta a lo dicho en el texto la considerac:ón de que las modificaciones muy importantes de Ordenanzas deban ser consideradas como materia similar a la imposición, según reconoce la sentencia del Tribunal Supremo de 1 de julio de 1859. 
gal y teóricamente están definidos perfectamente en la actualidad: a) acuerdo de imposición, es decir, ejercicio por la Corporación de la facultad impositiva que se le reconoce por la Ley; b) aprobación de la Ordenanza, es decir, del régimen de aplicación, tarifas, formación de documentos, cobro de cuotas que se liquiden por la exacción previamente impuesta, etc. (3), por la propia Corporación; c) aprobación de la imposición y de su Ordenanza reguladora por los órganos del Estado a que se confía el control de la política fiscal de las Corporaciones locales (nos referiremos tan sólo a la Delegación de Hacienda) ; y d) aplicación y efectividad de la imposición con arreglo a su Ordenanza, con liquidación y giro de cuotas a los contribuyentes afectados (4).

Todos los actos administrativos de los cuatro grupos precedentes son reclamables, en interés de los particulares y hasta de la propia Corporación titular de la imposición. Así, contra la imposición de una nueva exacción, pretendiendo su modificación . nulidad, caben: 1) Durante el período de exposición al pú- blico del acuerdo de actuarla, cabe reclamación simplemente administrativa ante la Corporación local por los interesados, que será resuelta por el Delegado de Hacienda, a la vez que se pronuncia sobre el acuerdo de imposición (arts. 722 y 723 de la Ley

(3) Este trámite puede omitirse en alguna exacción, como la de contribuciones especiales, conforme indica el articulo $18 \mathrm{del}$ vigente Reglamento de Haciendas lucales, que no consideramos muy conforme con el artículo 717 de la Ley de Régimen local en vigor (691 de la de 1950), ni con la Base 64 de la Ley de 17 de julio de 1945.

(4) Todavia podria admitirse otro periodo intermedio para aquellas exacciones cuyo cobro exige la formación y aprobación corporativa de un padrón. Pero no consideramos este momento de la gestión con substantividad, porque, además de que no es general, no obsta el que no haya oposición al padrón durante su exposición al público -que sería simplemente administrativa, ante la propia Corporación, que resolveria - para recurrir en la vía económico-administrativa contra las cuotas en él figuradas como si de un caso de aplicación singular se tratara; a este efecto, determina el párrafo $3 .^{\circ}$ del artículo 238 del Reglamento de Haciendas locales cuándo ha de entenderse notificada la liquidación. Sans Buigas, en Keclamaciones procedentes contra las cuotas fiscales aplicadas previa matricula o padrón (aRevista Moderna de Administración Local»; núm. 542, junio 1956), sostiene que no cabe formulación de reclamación alguna durante el período de exposición al público. 
de Régimen local vigente). 2) Contra el fallo estimatorio - a interponer por la Corporación- o desestimatorio - a interponer por el particular-, de la precedente reclamación, así como del acuerdo de imposición, recurso gubernativo de alzada ante el Ministro de Hacienda (art. 725 de la Ley de Régimen local). 3) Contra la resolución del Ministro de Hacienda, recurso contencioso-administrativo ante el Tribunal Supremo (art. $725 \mathrm{de}$ la Ley de Régimen local), cuyo fallo es ya cosa juzgada formal y material. Del mismo modo, contra la aprobación de una Ordenanza o su variación, pretendiendo su modificación, caben : 1) Reclamación simplemente administrativa ante la Corporación local durante el plazo de exposición al público, que será resuelta por la Delegación de Hacienda (arts. 722 y 723 de la Ley de Régimen local). 2) Contra la resolución del Delegado de Hacienda puede interponerse por los particulares afectados o por la Corporación interesada recurso contencioso-administrativo ante el Tribunal provincial, que, por ser en única instancia, decide definitivamente la cuestión $\mathrm{y}$ ha de ser observado en el futuro (artículo 726) (5).

Pero sólo caben las reclamaciones económico-administrativas contra los actos incluídos en el apartado $d$ ) de los precedentemente expresados, es decir, contra los actos de aplicación y efectividad, colectiva o singular, de la imposición de que se trate. Ahora bien, esto independientemente de que se hayan impugnado o no en las vías y en los momentos procedentes los acuerdos de creación y regulación de la exacción; e independientemente tam-

(5) Excede de los limites de este trabajo el estudio de la exorbitante competencia que se atribuye a los Tribunales provinciales contencioso-administrativos para sustituir la facultad reglamentaria de las Corporaciones locales, puesto que sus sentencias adeberán expresar concretamente la forma en que han de quedar redactados los preceptos impugnados»; el mismo alcance se da a las resoluciones de los Delegados de Hacienda. Creemos que, en recta doctrina, estos órganos determinan la redacción que ha de darse a la Ordenanza recurrida o reclamada, pero que la misma no es derecho positivo en vigor en tanto que no sea asi aprobada por la Corporación, la cual debe poder prescindir de aplicar la exacción si la Ordenanza que ha de regularla no es estimada de aplicación eficaz. Vid., al respecto, Ortiz DíAz: El recurso contencioso-administrativo en la nueva Ley de Régimen local, Madrid, 19503, págs. 136-137 y 237-239. 
bién de que pueda ser recurrido el acuerdo de imposición o de aprobación de la Ordenanza en la vía contenciosa, que es la única procedente, a pesar de que se estén ya apiicando uno y otro, en el caso de que con anterioridad no se haya llegado a la producción de la cosa juzgada material al respecto, o sea, si la jurisdicción contencioso-administrativa no se ha pronunciado sobre la validez de la imposición y la licitud de su Ordenanza (6).

En la exclusiva admisión de reclamaciones económico-administrativas contra los actos de aplicación y efectividad de las exacciones locales, y no contra los de imposición o regulación de las mismas, están de acuerdo todos los autores (7), así como la jurisprudencia (8), apoyados en la legislación que acabamos

(6) Téngase en cuenta que, conforme el artículo 219 del Reglamento de Haciendas locales, la imposición y ordenación de exacciones puede ser impugnada en la via administrativa en los ejercicios sucesivos adurante el plazo que en cada uno de ellos esté expuesto al público el Presupuesto en que figuren inclu:das», como si se tratase de la primera vez que se acuerdan o aprueban; nada impide que al mismo tiempo se entable una reclamación económico-administrativa contra la cuota girada por una exacción en un determinado ejercicio económico, basándose para la impugnación en el articulado de la Ordenanza, y una reclamación simplemente administrativa pretendiendo la nulidad de la imposición o la modificación de su Ordenanza para los ejercicios siguientes. Al margen de esta posibilidad periódica de impugnación administrativa que resolvería el Delegado de Hacienda, está el posible recurso directo contencioso-administrativo contra los acuerdos de imposición u ordenación, que escapa a los objetivos de este estudio; vid., por ejemplo, Garrido Falla: Régimen de impugnación de los actos administrativos, Madrid, 1956, págs. 162 y ss.

(7) l'ueden verse: Garrido Falla: op. cit., págs. 81 y ss.; Ortiz Díaz: op. cit., págs. 132-138; GonzÁlez PéREz, entre otros, en El proceso contenciosoadministrativo en materia de Haciendas locales, RevisTA DE EsTUdios DE LA VIDA Local, núm. 56, páy. 173 del vol. de 19́51, y Comentario al Decreto de competencias de 10 de febrero de 1955, en aRevista de Administración Públican, núm. 16, págs. 169172 ; Royo Villanova: Problemas del régimen juridico municipal, Madrid, 1944, págs. 195-215; Abella, Barros, Marqués Carbó, en sus comentarios a la legislación local, etc. La generalidad de estos autores distinguen los regímenes de imposición, ordenación y aplicación de las exacciones; nosotros, admit:endo esta misma tripartición, hemos marcado como momento incependiente aquél en que la imposición y la ordenación son autorizadas (definitivamente o no) por la vía administrativa central.

(8) Fntre otras, pueden verse las sentencias del Tribunal Supremo de 24 de junio de 1929 , 25 de mayo de 1940, 18 de diciembre de 1943; 30 de marzo de 1953, 15 de junio de 1955, 14 de octubre de 1959, etc.; el Decreto de competencias de 10 de febrero de 1955 (con el comentario citado de González Púrez y el de 
de citar o en su inmediata precedente (porque, como veremos seguidamente, el sistema de recursos y reclamaciones contra las exacciones locales vigente procede de los Estatutos, y, principalmente, del municipal). Por eso, nos atrevemos a suponer que no ha sido voluntario su olvido en el artículo 42 del Reglamento de 1959, máxime cuando en su Exposición de motivos no se hace alusión alguna a tan importante y revolucionaria innovación.

El principio de que se trata y la distinción entre los cuatro momentos procesales, antes expresados, aparece claramente consagrado en el Derecho positivo local vigente. Ni en los artículos 722 y siguientes de la Ley de Régimen local vigente ni en los concordantes de su Reglamento de Haciendas se ha articulado una reclamación económico-administrativa contra los acuerdos de imposición de exacciones locales ni contra los aprobatorios de sus Ordenanzas o de modificaciones de éstas; las reclamaciones que se arbitran contra los mencionados actos generales son ciertamente de materia económico-administrativa, pero no tienen la naturaleza jurídica procesal que las somete a los Tribunales de esta jurisdicción administrativa. Los Tribunales provinciales de esta vía (con competencia exclusiva, según los artículos 729. de la Ley de Régimen local y 10 del nuevo Reglamento de estas reclamaciones) conocen únicamente de las cuestiones que se susciten con motivo de la aplicación de las exacciones y sus Ordenanzas, es decir, contra la aplicación y efectividad de las exacciones locales.

Este sistema de impugnaciones procede, como hemos dicho ya, del Estatuto municipal de 8 de marzo de 1924, cuyos artículos 317,323 y 327 articulan un cuadro de reclamaciones simplemente administrativas, económico-administrativas y contenciosas igual al vigente. Su Exposición de motivos, decía a este respecto: "Los acuerdos sobre establecimientos de imposiciones municipales serán impugnables en la vía económico-administrativa, ante la Delegación, primero, y ante el Ministerio del ramo, des-

\footnotetext{
Martínez Palacio, en Los derechos y tasas por prestación de servicios y recursos procedentes, en aRevista Moderna de Administración Local», núm. 547, noviembre 1956); la resolución del Tribunal Económico-administrativo central de 13 de octubre de 1850 , etc.
} 
pués; dánḍose esta segunda instancia gubernativa por la trascendencia técnica y financiera que tienen aquellas resoluciones; y los acuerdos sobre efectividad y cobro de exacciones municipales tendrán una instancia administrativa ante el Tribunal provincial de Arbitrios" (hoy Tribunal provincial económico-administrativo); merece la pena resaltar la imprecisión terminológica del párrafo transcrito, puesto que no es vía económico-administrativa la reclamación ante el Delegado de Hacienda, ni siquiera la alzada ante el Ministro del ramo (que ya es, en otros asuntos, órgano de esta jurisdicción). Pero, evidentemente, no puede basarse en este error terminológico del preámbulo, desvirtuado en la articulación del cuerpo legal, la admisión de reclamaciones de este tipo contra los actos de imposición de exacciones locales.

Sabido es que la legislación de la República dejó subsistentes los Estatutos municipal y provincial en sus respectivas partes fiscales, con excepciones que no son del caso, por lo que continuaron al respecto en vigor hasta la legislación del nuevo régimen.

La Base 64 de la Ley de 17 de julio de 1945, unificando de nuevo el régimen de las Provincias y los Municipios, sigue las directrices del Estatuto municipal, admitiendo contra los acuerdos de imposición de nuevas exacciones y aprobación o modifcación de sus Ordenanzas recurso ante la Delegación de Hacienda, cuya resolución podrá ser recurrida en alzada ante el Mrnisterio de Hacienda, si se trata de imposición de exacciones, y ante el Tribunal Contencioso-administrativo en los demás casos; el sistema es, pues, semejante al del Estatuto municipal, aunque no se alude al carácter de las reclamaciones contra la aplicación y efectividad de las exacciones.

El Decreto de ordenación provisional de las Haciendas locales, de 25 de enero de 1946, establece en sus artículos 271-273 un régimen igual al que hemos visto contiene la Ley de Régimen local de 1955 , cúyos artículos 722 a 730 son en lo que ahora nos interesa copia también de los 694 a 702 de la Ley de 16 de diciembre de 1950.

Con arreglo a la legislación local en vigor, conforme al principio que se arrastra desde el Estatuto municipal, sólo caben 
reclamaciones económico-administrativas contra los actos singulares o colectivos (padrones fiscales) de aplicación de las Ordenanzas de exacciones, pero no contra los acuerdos de imposición $u$ ordenación de las mismas. ¿ Se ha pretendido implantar un nuevo sistema en el Reglamento de 26 de noviembre de 1959 ?

\section{2) Legislación del procedimiento económico-administrativo.}

Ya hemos dicho que el artículo 42 del Reglamento de $\mathbf{1 9 5 9}$ copia literalmente en lo que ahora nos interesa al artículo 23 del de 1924 ; el anterior Reglamento de 13 de octubre de 1903 no contenía mención sobre el extremo ahora debatido.

Dada la inmediata proximidad de los textos de que arrancan, en lo que ahora nos importa, los sistemas local y económico-administrativo (Estatuto municipal, 8 de marzo de 1924; Organización de lo económico-administrativo, 16 de junio; Reglamento del procedimiento de esta vía, 29 de julio; Reglamento del procedimiento municipal, 23 de agosto), la duda sobre la posible derogación del Estatuto por la admisión de estas reclamaciones contra los actos de imposición u ordenación que establecía el artículo 23 de su Reglamento debió producirse inmediatamente, bien por el juego de la sucesiva publicación de unos y otros textos, bien por la no comprensión correcta del sistema instaurado por el Estatuto. Pero la cuestión quedó ya resuelta por las Reales Ordenes de 24 de noviembre de 1924 y 20 y 29 de julio de 1925 (9) y ha sido reiteradamente y con criterio uniforme de-

(9) Dice la R. O. de 24 de noviembre de 1924, dictada para resolver dudas suscitadas sobre qué personas deberian formar parte de los Tribunales provinciales para entender de reclamaciones locales, đy a cuá'es de estas reclamaciones se extiende la competencia de tales organismosn: aConsiderando que, conforme con las disposiciones del vigente Estatuto municipal y de los reglamentos para su aplicación, es necesario distinguir, a los efectos del procedimiento, entre la imposición de las exacciones y la aplicación y efcctividad de las mismas. Considerando, en relación con la imposición de cxacciones municipales, que ninguna intervención tiene en las reclamaciones que puedan succitarsa el Tribunal económico-admin:c. trativo provincial, ya que el atticulo 31.7 del me:cionado Estatuto y el 64 ce procedimiento municipal del 23 de axcs": $\because$ 'timn. determinan la compete:icia a favor de los Delegados de Haciercí. essurancio e! recurso de alzada contra stos acueadss pura arte e! Ministerio del ramo.... 
finida por la jurisprudencia posterior, como ya hemos visto, en el sentido sostenido precedentemente.

Parece, pues, que al copiar el artículo 23 de 1924 se debiera haber tenido en cuenta el principio legal a que nos referimos, y haber excluído del artículo 42 vigente el párrafo de que use entenderán comprenáidas en este caso las reclamaciones sobre exacciones locales que se refieran a la modificación o nulidad de las mismas".

Pero es que, además, se ha olvidado que el precepto de 1924 no estaba en concordancia con el Decreto orgánico de la jurisdicción, que, con arreglo a la disposición adicional tercera de éste, venía a desarrollar. En efecto, el artículo $1 .^{\circ}$ del Decreto orgánico de 16 de junio de 1924 establecía que a los Tribunales económicoadministrativos provinciales competía también "el conocimiento de todas las reclamaciones sobre aplicación y efectividad de las exacciones municipales, en la forma determinada en el artículo 327 del Estatuto municipal vigente) ; se debió, pues, seguir en el Reglamento del procedimiento el sistema establecido en el Estatuto municipal. que ya hemos expuesto, y, con arreglo a la determinación de este precepto orgánico, limitarse a regular las reclamaciones sobre aplicación y efectividad, con abstracción de las que pretendieran la modificación.o anulación de los acuerdos de imposición $u$ ordenación de las exacciones, que, tácitamente, quedaban excluídas de esta jurisdicción (10).

Refundidas en el vigente Reglamento de estas reclamaciones, las materias orgánica y de procedimiento, aparece, no obstante, en el mismo la discordancia entre sus preceptos básicos y el artículo 42 que nos ocupa. Su artículo $1 .^{\circ}$, al precisar el ámbito de

(10) El Reglamento de 29 de julio de 1924 resulta así praeter legem (regula algo đademás de lo que» contenia el Decreto orgánico que desarrolló) y hasta cciitra lcgem (va contra el sistema establecido sobre el particular por el Estatuto municipal, cuyos principios aceptaba el Decreto orgánico). Pero esto, por desgracia, y pese a la jurisprudencia sentada por el Tribunal Supremo reiteradamente, es demasiado frecuente. Quizá se consiga disminuir el número de estos casos con las tajantes disposiciones de las leyes de Régimen juridico de la Administración del Estado y de la de Procedimiento administrativo, asi como con la posibilidad de impugnación directa de las disposiciones generales que establece la nueva Ley de la Jurisdicción oontencioso-administrativa. 
aplicación de sus normas, dice en su párrafo segundo que se entenderá por reclamación económico-administrativa la que se deduzca en relación con las materias siguientes: "c..e) Aplicación $y$ efectividad de las exacciones de las Haciendas locales, sus presupuestos y demás materias determinadas como reclamables en la Ley de Régimen locall"; aquí, en este precepto básico que hurta con un sistema enumerativo el difícil problema de sentar una definición sintética de lo que deba entenderse por reclamación económico-administrativa, se habla sólo de aplicación y efectividad de exacciones, en plena conformidad con la legislación local, como hemos dejado bien sentado, y a estas únicas impugnaciones debiera haberse referido el artículo 42 del mismo Reglamento, en vez de aludir también, como hace, a las de los acuerdos de imposición y ordenación de aquéllas; las impugnaciones a que den lugar estos acuerdos serán simplemente administrativas (ante la Corporación, resueltas por el Delegado de Hacienda), gubernativas (de alzada ante el Ministro del ramo), o contencioso-administrativas (ante el Tribunal provincial o Supremo), pero nunca económico-administrativas (ante los Tribunales provinciales de esta jurisdicción).

El tan debatido artículo 42 está, pues, gritando su incongruencia, en lo que ahora nos importa, no sólo con el Derecho positivo local vigente, sino también con la propia sistemática del Reglamento en que se contiene.

\section{3) "De iure condendo".}

En lo que antecede creemos que queda evidente la indudable vigencia en el Derecho positivo, en la doctrina y en la jurisprudencia del sistema de recursos que en materia de exacciones locales estableció el Estatuto municipal, y el error que comete el artículo 42 del Reglamento que comentamos al admitir como reclamaciones económico-administrativas colectivas impugnaciones que no tienen en recta técnica procesal la naturaleza de reclamaciones económico-administrativas.

La argumentación se refuerza con la consideración de que el artículo 238 del Reglamento de Haciendas locales vigente, al 
enumerar las materias sujetas al procedimiento de revisión económico-administrativo, no incluye los actos de imposición u ordenación de exacciones.

Creemos que, con base en el Derecho positivo vigente, todo Tribunal de esta jurisdicción administrativa debe abstenerse de cualquier reclamación, colectiva o no, que ante él se formule pretendiendo la modificación o anulación de alguna Ordenanza o exacción. $Y$, si esta acción fuere encubierta al amparo de una reclamación sobre procedencia de cuotas, deberán pronunciarse sobre este último particular aplicando el derecho objetivo que es la Ordenanza en vigor, pero sin entrar a decidir sobre la legalidad de la imposición o su Ordenanza, materias éstas que, a pesar de lo que establece el artículo 46 sobre el alcance de la revisión, exceden de la competencia de estos órganos.

No obstante, estando en trance de revisión la legislación local, creemos conveniente llamar la atención sobre este particular, considerando oportuno que se declare expresamente por la nueva Ley de Régimen local la improcedencia de reclamaciones económico-administrativas contra los acuerdos de imposición $\mathrm{u}$ ordenación de exacciones. Aunque, como queda dicho, consideramos un simple error de copia indiscriminatoria la alusión a estas reclamaciones que hace el artículo 42 del nuevo Reglamento, convendría desvirtuarlo legalmente, puesto que estimamos que debe ser mantenido el sistema de impugnaciones en materia de exacciones locales establecido por el Estatuto municipal: a) porque tiene ya una respetable tradición de más de un tercio de siglo; $b$ ) porque la vía administrativa ante el Delegado de Hacienda con alzada (en materia de nuevas exacciones) ante el Ministro es más rápida y eficaz que la económico-administrativa, y c) porque tanto después de la vía administrativa como independientemente de ella en los casos de impugnación directa que se admiten ahora, resta siempre a los particulares (y a la propia Corporación), la suprema garantía de la jurisdicción contencioso-administrativa. 
B) Las reclamaciones económico-administrativas contra la aplicación de exacciones localcs pueden ser colectivas

También estimamos desacertado el artículo 42 del nuevo $\mathrm{Re}$ glamento de estas reclamaciones cuando dice en su inciso final que las que se entablen contra la procedencia de las cuotas impuestas “deberán ser siempre individuales y entablarse por los propios interesados o por sus legítimos representantes». Examinemos la cuestión desde el punto de vista del Derecho positivo y de la reforma prevista de la legislación local:

\section{1) Examen del Derecho positivo.}

El precepto que nos ocupa es también en esta parte copia literal del de 1924 ; pero éste había nacido ilegal y quedó sin vigor al poco de su promulgación, extremos que parece no se han tenido en cuenta en 1959. En efecto, el Estatuto municipal (único en el que se plantea la cuestión y que, como hemos dicho es base del régimen uniforme local vigente hoy) había establecido en su artículo 327 que "todas las reclamaciones sobre aplicación y efectividad de exacciones municipales tendrán carácter económico-administrativo a los efectos del procedimiento. Estas reclamaciones podrán ser colectivas cuando afecten en forma y por motivos similares a varios contribuyentes"; el artículo $1 .^{\circ}-2$ del Decreto orgánico de 16 de junio siguiente se limitó a establecer, como hemos visto, la competencia de los Tribunales provinciales en esta materia "en la forma determinada en el artículo 327 del Estatuto municipal vigente». Por ello, el Real Decreto de 29 de julio del mismo año que reformó el procedimiento para adaptarlo al Decreto orgánico (tercera disposición adicional de éste), debió seguir las directrices de la disposición que venía a desarrollar, y, a través de ella, del Estatuto municipal, admitiendo las reclamaciones colectivas contra la procedencia de las cuotas impuestas, es decir, contra los actos de aplicación y efectividad de las exacciones. Por el contrario, fué uno de los muchos reglamentos 
que van en contra de las disposiciones que desarrollan, y, por. ello, ilegales.

Pero, además de haber nacido ilegal, el Reglamento económico-administrativo de 1924 fué derogado en la parte que nos interesa al poco de nacer. El Reglamento de procedimiento en materia municipal de 23 de agosto de 1924, comprendiendo la sinonimia de los conceptos "aplicación y efectividad de exacciones» y "procedencia de las cuotas impuestas", estableció terminantemente en su artículo 61 que, "con arreglo a lo dispuesto en el artículo 327 del Estatuto, las reclamaciones sobre modificación o nulidad de exacciones municipales o procedencia de las cuotas impuestas podrán ser colectivas y entablarse conjuntamente por aquellas personas a quienes el mencionado texto legal reconoce este derecho, quedando sin efecto lo establecido acerca de este particular en el numero $2 .^{\circ}$ del artículo 23 del Re glamento de Procedimiento económico-administrativo de 29 de julio de 1924" (11). Parece, pues, como si con esta mención expresa se hubiera querido desvirtuar cualquier duda sobre la materia motivada por la contradicción entre el Estatuto y el Reglamento que se declara derogado al respecto; este objetivo se trasluce del hecho de haber sido resaltado este precepto en el Preámbulo del ordenamiento procedimental municipal, puesto que, aunque con no muy correcta ilación con el párrafo precedente, se dice en ella que "destaca el relativo a las reclamaciones colectivas, que siempre serán lícitas y legales cuando se promuevan contra exacciones municipales, por cualquier motivo; con esta declaración queda reafirmado el correspondiente artículo del Estatuto, que

(11) Tanto en el artículo 61 de este Reglamento como en su correspondiente 240 del Reglamento de Haciendas locales de 1952, se reúnen para admitirlas colectivamente las reclamaciones contra los acuerdos de imposición (nulidad de exacciones), ordenación (modificación de exacciones) y aplicac:ón de exacciones (procedencia de cuotas); podría inducirse de esta consideración conjunta que se da a todas estas impugnaciones el carácter de reclamaciones económico-administrativas, desvirtuando así lo que dejamos sentado en el apartado II) A) de este trabajo. Nos remitimos a lo alli dicho; en estos preceptos se están considerando las reclamaciones de todo orden (simplemente administrativas, de alzada, económico-administrativas) que caben en materia de exacciones locales, y se establece el principio de que todas ellas pueden interponerse colectivamente. 
corresponde a inexcusables anhelos de ciudadanía y es por ello fundamentaln.

Quedó, pues, expresa y terminantemente establecido que, a pesar de lo que disponía el Reglamento de las reclamaciones económico-administrativas, éstas podían interponerse colectivamente cuando se refirieran a la aplicación y efectividad de las exacciones locales, impugnando la procedencia de las cuotas impuestas. Este principio llega a través de la permanencia del régimen: fiscal del Estatuto en la Ley de 1931-1935 al artículo 273 del Decreto de ordenación provisional de las Haciendas locales, de 25 de enero de 1946 (12), al artículo 699 de 1950 y al 727 de 1955, siendo. todos éstos copia casi literal del artículo 327 del Estatuto municipal; y, del mismo modo, el Reglamento de Haciendas locales de 1952 mantiene en su artículo 240 la cláusuia derogatoria del 23 del de procedimiento económico-administrativo.

Al expresar ahora el Reglamento de 1959 que las reclamaciones contra la procedencia de las cuotas impuestas no pueden ser colectivas, hemos de plantearnos la cuestión de si ha querido romperse con el sistema precedente o, simplemente, si se trata de otra consecuencia de la copia que, inadvertidamente, se ha hecho de un precepto derogado; el problema se agudiza si tomamos en consideración el alcance derogatorio de la segunda disposición final del nuevo Reglamento.

Para averiguar, pues, lo que se ha querido hacer respecto de las reclamaciones colectivas en el vigente ordenamiento procesal de las económico-administrativas, hemos de utilizar tres puntos de referencia:

a) La interpretación sistemática del Reglamento de 1959: $\mathrm{Su}$ artículo 42 dice que sólo pueden interponerse colectivamente las reclamaciones que pretendan la modificación o anulación de imposiciones; pero estas reclamaciones hemos visto en II) A) que no son económico-administrativas; luego, enton-

(12) Con base en este Decreto admite FÁbregas del Pilar las reclamaciones colectivas, en Procedimiento en las reclamaciones económico-administrativas, 2.* edición, Madrid, 1950 , págs. 556 y $640 ;$ y, con base en los textos siguientes, Garcfa Ortiz, op. cit., píg. 13ï; Garcfa Oviedo-Martf́nez Useros en Derecho administrativo. 7.a erición. Máárid, 1959, pág. 6711; Barros, op. cit., pág. 866 ; etc. 
ces, no cabría ninguna reclamación económico-administrativa, en materia de exacciones locales, que pudiera interponerse colectivamente: y el párrafo aclaratorio del número segundo de este artículo carecería de sentido, lo que, indudablemente, no puede admitirse, aunque está implícito en el contenido global del Reglamento.

b) La relación con el Derecho positivo local : El Reglamento de 1959 copia al de 1924 ; pero éste, además de haber nacido ilegal, fue derogado expresamente por otra disposición de igual rango (el Reglamento de procedimiento municipal de 1924) y, recientemente, por el Reglamento de Haciendas locales de 1952, que sigue las directrices de la Ley de Régimen local de 1950, concordantes con las del Texto refundido de 1955, cuyo artículo 727 claramente establece que las reclamaciones sobre aplicación y efectividad de exacciones podrán ser interpuestas colectivamente "cuando afecten en forma $y$ por motivos similares a varios contribuyentes". De esto parece que no se ha dado cuenta el legislador de 1959, porque, si lo hubiera advertido, hubiera acogido el régimen local, so pena de dictar un Reglamento ilegal, o, si hubiera estimado más oportuno ir contra él aún a trueque de la ilegalidad del Reglamento, hubiera figurado al menos un precepto de derogación expresa del mismo, (como hizo el de procedimiento municipal de 1924, como hace el de Haciendas locales de 1952), resaltada en el Preámbulo. $\mathrm{Y}$ no se ha hecho ninguna de las dos cosas: simplemente, se ha copiado un precepto derogado que está en pugna con la Ley de Régimen local vigente.

c) Alcance de la cláusula derogatoria del Reglamento de 1959: Podría argüirse que la derogación de los preceptos locales que admiten las reclamaciones colectivas se ha hecho por la cláusula derogatoria del Reglamento, que dice: "Quedan derogadas, en cuanto se refiere al conocimiento, tramitación y resolución de las reclamaciones económico-administrativas, el Real Decreto-ley de 16 de junio de 1924, el Reglamento de 29 de julio de 1924, la Ley de 9 de mayo de 1950 y demás preceptos legales vigentes hasta ahora en la materia". Este razonamiento tiene más valor si se esgrime también el hecho 
de que el Texto refundido de la Ley de Régimen local de 1955 fué aprobado por Decreto, como el Reglamento de 1959 y el de Haciendas locales de 1952. Pero, aun admitiendo que la materia que nos ocupa puede ser encuadrada entre las de conocimiento o tramitación a que alude la cláusula derogatoria, hemos de tener en cuenta: 1) Que los textos de 1950 y 1955 de la Ley de Régimen local son desarrollo de la Ley de Bases de 17 de julio de 1945 (y de la de 3 de diciembre de 1953), teniendo, por consiguiente, rango de leyes, como en los mismos textos y en constantes alusiones de otros se reconoce multitud de veces, por lo que no pueden ser derogadas por disposiciones administrativas como son los Decretos, a menos que éstos obedezcan a autorización expresa conferida por Ley, caso éste que no se da en lo que nos ocupa (13). 2) Que la derogación de disposiciones de superior rango por el Reglamento de 1959 es lógica consecuencia de ser una abrogación o sustitución de aquéllas en las materias que unas y otro regulan, como sucede con las que cita expresamente la disposición final segunda. 3) Que la admisión de las reclamaciones colectivas está más en consonancia con los imperativos de economía procesal a que repetidamente alude la Ley de Procedimiento administrativo de 17 de julio de 19.58, en cumplimiento de cuya disposición final tercera $y$ para ser adaptado a ella se publicó el Reglamento de 1959 ; la excepción al principio de economicidad que se introduce en el artículo 42 de éste es tan grande que bien debiera haberse aludido a ella en la Exposición de motivos del ordenamiento,

(13) Artículos 28 y 26 de la Ley de Régimen jurid:co de la Administración del Estado; artículo 47 de la Ley de Procedimiento administrativo. Fera Verdaguer no se plantea el problema general del alcance de la cláusula derogatoria de este Reglamento al comentar su disposición final $2^{\mathrm{a}}$ en Procedimiento económico-administraivo, Barcelona, 1960, aunque, como veremos, no le concede efectividad sobre la Ley de Régimen local; no se plantea tampoco el problema de las reclamaciones colectivas que estamos estudiando, al comentar el artículo $\mathbf{4 2}$ de este nuevo ordenamiento. En cambio, wa Administración Práctican, en sus comentarios al Reglamento de 1959, números de enero, febrero y marzo de 1960 , admite, de plano y sin dar razón alguna, la derogación por él de la Ley de Rég:men local, y, concretamente, sostiene la inadmisibilidad hoy de las reclamaciones colectivas, en su pág. 65. 
máxime cuando la legalidad vigente era más favorable al principio conculcado.

De la consideración de estos tres puntos de referencia parece razonable deducir que el Reglamento de 1959 no ha pensado en su'primir la posibilidad de impugnar colectivamente las cuotas impuestas por exacciones locales cuando afecten en forma y por motivos similares a diversos contribuyentes, y que la legalidad vigente en esta materia está en la Ley de Régimen local de 1955 y en su Reglamento de Haciendas locales.

2) "De iure condendo".

En trance de revisión quinquenal la legislación local, con lo que se dará también cumplimiento a lá disposición final cuarta de la Ley de Procedimiento administrativo, creemos conveniente dejar sentado que, respecto de la cuestión que nos ocupa ahora, debe consagrarse de nuevo sin lugar a dudas el sistema establecido al respecto por el Estatuto municipal y recogido hoy en el Texto de $\mathbf{1 9 5 5}$ y en el Reglamento de Haciendas locales: que las reclamaciones económico-administrativas contra las exacciones locales pueden ser interpuestas colectivamente. Estimamos que en lo que antecede ha quedado evidente que el Reglamento de estas reclamaciones de 1959 ni ha pretendido ni ha logrado derogar el referido régimen local; pero para evitar posibles vacilaciones en la aplicación de la legislación en vigor por los Tribunales de esta jurisdicción (quizás más prestos a utilizar exclusivamente el ordenamiento procesal de la misma que a coordinarlo con la legislación local) y para precaver posibles disparidades de criterios interpretativos del Derecho positivo vigente en la materia, sería muy conveniente que se aclarara definitivamente la cuestión. Lo que bien podría hacerse mediante una disposición "ad hoc" que diera al artículo 42 del nuevo Reglamento económico-administrativo la interpretación que lo concordara con el Derecho local, y también manteniendo en la revisión que se tramita de éste los preceptos de los artícu'os 727 del Texto de 1955 de la Ley y 240 de su Reglamento de Hacien- 
das, incorporando ahora a éste la derogación expresa del artículo 42 del Reglamento de 1959.

Tenemos la certeza de que la práctica y la jurisprudencia consagrarán la pervivencia de la admisión de reclamaciones colectivas. Pero sería mejor que la cuestión se decidiera con carácter general, aun a trueque del desconcierto que produce la sucesiva y rápida derogación de disposiciones inmediatas.

$\mathrm{Ya}$ vimos que para el legislador municipal de 1924 se consideraba la admisión de las reclamaciones colectivas contra las exacciones como un inexcusable anhelo de ciudadanía, principio fundamental de la vida político-administrativa. Esta columna básica del régimen local, hoy uniforme, debe ser de nuevo reafirmada en la revisión que se gesta del mismo para no dejar resquicio alguno sobre la duda de su vigencia; porque la conveniencia del sistema es quizás ahora mayor que entonces, y se basa, fundamentalmente, en las siguientes consideraciones:

a) Desde el punto de vista histórico, porque ha sido tónica general de los ordenamientos locales desde el Estatuto mumicipal, treinta y cinco años antes de la promulgación del $\mathrm{Re}$ glamento de 1959.

b) Desde el punto de vista jurídico-práctico, porque se halla más en consonancia con los principios de economia procesal señalados por la Ley de Procedimiento administrativo: Supongamos, por ejemplo, un expediente de aplicación de contribuciones especiales en el que gran parte de los afectados estime que se les han derivado cuotas muy altas como consecuencia de haber aplicado valoraciones excesivas a sus propiedades; la reclamación es, evidentemente, económico-administrativa y contra la procedencia de las cuotas impuestas. Pues bien, ¿ habría de entablarse una reclamación individual por cada uno de los contribuyentes afectados?; ¿no es mucho más rápido y económico procesalmente que pueda interponerse una única reclamación colectiva por todos los afectados, puesto que la afección es wen forma y por motivos similares"?; ¿no es, incluso, más conveniente que, aunque las reclamaciones se presentaran individualmente, pudiera decretarse de oficio o a petición de los in- 
teresados la acumulación de las actuaciones por el Tribunal al amparo de lo que establece el artículo 51 del mismo Reglamento económico-administrativo, lo que con arreglo al tenor literal de su artículo $42-2 .^{\circ}$ no podría hacerse? (14).

c) Desde el punto de vista político, porque con la posible reclamación colectiva quedan mejor salvaguardados los intereses de los particulares, que tendrán más expedita la vía de recurso y verán minorados los costos de éste. $Y$, también, se beneficia de este modo la sana Administración, puesto que sus órganos se verán coaccionados por el mayor alcance de sus posibles errores, contribuyendo así a la meticulosidad de la actuación administrativa (15).

\section{III) La AUdiencia de la Corporación INTERESAda}

El artículo 730 de la Ley de Régimen local vigente, dice que "en las reclamaciones económico-administrativas sobre aplicación y efectividad de exacciones se dará nécesariamente audien cia a la Corporación local interesada, por un plazo de quince días, que se contará a partir de la fecha en que se le notifique la presentación por el reclamante del escrito de alegaciones".

(14) Conviene llamar la atención sobre otro posible caso: Que uno de los afectados por las contribuciones especiales interpusiera reclamación contra 'la cuota a él Gerivada por haberse deducido ésta de una aplicación defectuosa de Ios complicados preceptos que regulan este procedimiento, error que afecta a todo el reparto del expediente; en este supuesto, el Tribunal habria de pronunciarse sobre la legalidad de las actuaciones de gestión, conforme a lo que establecen los articulos 46 y 107-4 del Reglamento de procedimiento, por lo que, al decretar 1a rectificación del expediente tramitado, $\mathrm{su}$ fallo afectará a los contribuyentes que no reclamaron; una reclamación individual produciria asi efectos erga omnesp. Pero, en la hipótesis planteada en el texto, cada reclamación individual no afectaria más que a su actor, presumiéndose que el resto de los contribuyentes, si no reclaman, están conformes con la valoración estimada en las actuaciones de gest:ón.

(15) Con vistas indudablemente a este más eficaz control de la Administración, admitia el Reglamento económico-administrativo de 13 de octubre de 1903 en su articulo 27 , casi igual en lo demás al 23 de su inmediato de 1924, las reclamaciores colectivas acuando tengan por objeto denunciar abusos, ocultaciones o defraudaciones en perjuicio de la Hacienda, y, en general, toda clase de hechos de interés públicos. 
En el Reglamento de 1959 no se contiene precepto alguno que dé pie a configurar esta audiencia; antes al contrario, parece que se ha querido prescindir de la misma. Nos inclinamos abiertamente a la pervivencia de este trámite, y vamos a estudiar la cuestión desde el punto de vista del Derecho positivo y con vistas a la revisión de la legislación local.

\section{A) Examen del Derecho positivo}

El trámite de audiencia a la Corporación interesada fué introducido en el régimen local español por el Real Decreto-ley de 3 de noviembre de 1928, que introdujo reformas substanciales en el Estatuto municipal. $\mathrm{Ni}$ en los Estatutos ni en la anterior regulación del procedimiento económico-administrativo se concedía al Ayuntamiento una posibilidad de defender la improcedencia de la reclamación interpuesta; tal violación del principio fundamental del Derecho procesal «audi alteram partem» fué corregida por el Real Decreto-ley mencionado, cuyo artículo 15 estableció : "...Asimismo, en las reclamaciones económicoadministrativas sobre aplicación y efectividad de las exacciones. municipales, deberá ser oido siempre el Ayuntamiento que las: origine" (16).

Siendo subsidiario el Reglamento de procedimiento de estas reclamaciones de 1924 de las normas contenidas al respecto en el

(16) BARRos, $o p$. cit., pág. 877, dice que tan importante corrección del Estatuto. municipal fué fruto del Congreso municipalista celebrado en Zaragoza en el año 1928. Con anterioridad a este Real Decreto-ley, la Corporación no tenia más posibilidad de impugnar las alegaciones del reclamante, si eran estimadas a su juicio improcedentemente por el Tribunal, que recurrir ante la jurisdicción contenciosoadministrativa contra e!. fallo de aquél; el régimen de 1924 se limitaba a garantir los intereses del Municipio con la integración en el Tribunal provincial del Administrador de Rentas Públicas, en concepto de Jefe de la dependencia a que correspondía el asunto (art. 3 del Real Decreto orgánico de 16 de junio de 1924, aclarado por la Real Orden de 24 de noviembre del mismo año); hoy esta representación incumbe a los Jefes provinciales del Servicio de Inspección y Asesoramiento de las Corporaciones Locales (art. 729,2 del Texto refundido de la Ley de Régimen local). La Real Orden de 26 de noviembre de 1928 aclaró el Real Decreto-ley a que nos estamos refiriendo, y en su norma quinta refuerza la exigencia de esta audiencia. 
Estatuto y en el Reglamento procesal municipal (art. 57 de éste), era evidente que desde 1928 debía ofrecerse por el Tribunal provincial a la Corporación interesada el trámite de audiencia, aunque no se precisaba el momento en que debía producirse ni el plazo para ser cumplimentado. Se ofrecía, así, a la Administración municipal la posibilidad de que desvirtuara las alegaciones del reclamante, lo que a la vez podía llevar luz al órgano que habría de fallar.

Al desarrollarse la Ley de Bases del Régimen local uniforme para Municipios y Provincias de 1945, se copió casi literalmente, primero en el Decreto provisional de 1946 y luego en la Ley de 1950 (artículos 276 y 702, respectivamente), el párrafo tranșcrito del Real Decreto-ley de 3 de noviembre de 1928, sin aclarar las imprecisiones de éste, aunque dando al trámite el mismo carácter necesario (17).

El Reglamento de Haciendas locales de 1952 concretó que ef plazo de audiencia sería de quince días (art. 239-1), los mismos. que tenía el reclamante para formular su escrito de alegaciones. La Ley de Régimen local de $\mathbf{1 9 5 5}$ concreta que la audiencia de la Corporación habrá de producirse después de la presentación de sus alegaciones por el recurrente, y mantiene el carácter necesario del trámite.

Contra este Derecho local vigente, el Reglamento de 26 de noviembre de 1959, parece, hemos de reconocerlo, que quiere volver al sistema de no ofrecer a la Corporación afectada la defensa de la legalidad del acto reclamado. Bien es verdad que se abre ahora la posibilidad de una defensa previa del acto impugnado,

(17) Fábregas del Pilar, en Procedimiento en las reclamaciones económicoadministrativas, segunda edición, Madrid, 1950, pág. 644, y BAscones: Tribunales $y$ procedimiento económico-administrativo, Zaragoza, 1942, pág. 133, aceptan implicitamente la preceptividad de la audiência, pero no aclaran el momento ni el. plazo en el que ha de producirse; Marquts Carbó y Barros MarríNEz, ops. cits., se inclinan por la audiencia.tras la formulación por el reclamante de su escrito de alegaciones; SAEz LóPEz, en La audiencia de las Corporaciones recurridas ante el Tribunal Económico-administrativo, Revista General de Dẹrechon, núm. 133, págs. 783-787 del vol. de 1955, se inclina por que e! necesario trámite de audiencia se evacúe haciendo obligatoria la vista a que aludia e!. articulo 70 .del Reglamento económico-administrativo de $\mathbf{1 9 2 4 .}$ 
puesto que el artículo 95-3 establece que "con el expediente se remitirá (el plazo para ello, de cinco días en 1924, se ha doblado en 1959), también el informe de la oficina de gestión, cuando sea preceptivo, o, en general, cuando no consten expresamente en el expediente los motivos o fundamentos que determinaron el acto administrativon; cierto es también que la Corporación tiene en su mano el que se le tenga como parte en el procedimiento, personándose en él al amparo del artícuio 36 para que se entiendan con ella las actuaciones subsiguientes, personación que, por esta irretroacción del trámite, debe hacerse lo antes posible, siendo el momento más oportuno aquél en que, al reclamársele el expediente de gestión, conoce que se ha interpuesto el recurso. Pero, como veremos en $\mathrm{B}$ ), ninguna de estas dos posibilidades nos parecen bastantes para garantir al ente reclamado.

$\mathrm{Ni}$ la emisión de informe al remitir el expediente, ni la comparecencia en el procedimiento ya iniciado estaban consignadas en el Reglamento de 1924, aunque la última facultad cabría admitirse al socaire del párrafo final del artículo 63. Por ello, ha de reconocerse que el sistema de 1959 se implanta "ex novo", pretendiendo derogar el vigente a su promulgación, al contrario de lo que hemos sostenido en las otras dos cuestiones estudiadas.

Pero la audiencia de la Corporación interesada viene exigida reiteradamente desde 1928 por el Derecho local, con carácter significativamente marcado de necesario en ordenamientos que tienen rango de Ley. $\mathrm{Y}$ tanto por la tradicionalidad que tiene ya este trámite como por el carácter absolutamente imperativo que siempre, hasta en el texto de 1955 se le ha dado, y por el alcance que hemos sostenido debe darse a la cláusula derogatoria del Reglamento de 26 de noviembre de 1959 , creemos que no ha de entenderse suprimido por éste, y que no ha sido derogado el artículo 730 de la Ley de Régimen local, al que debe darse el más exacto cumplimiento (18).

(18) La Administración Práctica», loc. cit., págs. 30. 64 y 96, entiende, sin argumentarlo, que el Reglamento de 1959 ha derogado la legislación local por 1o que debe entenderse suprimido el trámite de audiencia. En cambio, Pera VerDaguer, op. cit., cita en su pág. 197, al comentar el articulo 97 del nuevo Regla- 


\section{B) "De iure condendo"}

Hemos apuntado ya que las novedades que el Texto de $\mathbf{1 9 5 9}$ introduce con respecto a su predecesor en esta materia hacen suponer que se ha querido suprimir el trámite de audiencia a la Corporación interesada en la reclamación, exigido necesariamente por la Ley de Régimen local. Y, con objeto de que quede disipada cualquier duda que pudiera plantearse sobre el particular (puesto que en la práctica, el principio de la jerarquía de las normas es frecuentemente conculcado, pese a la numerosa jurisprudencia que lo protege, y puesto que puede haber distintos criterios de apreciación sobre la prevalencia del ordenamiento procesal general o del ordenamiento especial local), conviene que la cuestión quede definitivamente resuelta, y con carácter expreso, aprovechando la revisión que se gesta de la legislación local.

Para justificar la conveniencia de que las Corporaciones locales sean oídas en las reclamaciones económico-administrativas a que dé lugar la aplicación y efectividad de sus exacciones, estimamos oportuno hacer las siguientes consideraciones:

1) La facultad de personación no es suficiente: Con arreglo al artículo 36 del Reglamento nuevo, podrán comparecer en el procedimiento ya iniciado todos los que ostenten derechos que puedan resultar directamente afectados por la resolución que hubiera de dictarse, entendiéndose con ellos la subsiguiente tramitación, pero sin que ésta pueda retroceder. Es evidente que la Corporación cuyo acto de aplicación se reclama se ve afectada (o se puede ver afectada) en el derecho que la Ley le concede a usar de la imposición, porque posiblemente se verá obligada a

mento. la: sentencias del Tribunal Supremo de 2 de enero de 1932 y 22 de octubre de 1956 , que declararon la nulidad de las actuaciones si no se dio audiencia a la Corporación recurrida, e, implícitamente, se declara por la pervivencia del Derecho local y, por consigu:ente, del trámite de audiencia; en sus comentarios a los artículo $10^{\circ}$ y 10 se manifiesta expresamente partidario de la legislación local al respecto. 
prescindir de unos ingresos que había ya concretado en uso de su potestad fiscal y reglamentaria; por ello, puede hacer uso de la facultad que establece este precepto para personarse en el procedimiento. Pero esta posibilidad no empece a la exigencia de la audiencia que por el Tribunal se le debe conceder: a) Porque la facultad de personación existía implícitamente reconocida durante la vigencia del Reglamento de 1924, cuyo artículo 63 en su párrafo final, como ya hemos indicado, considera el caso de que "se hayan personado en un expediente varios interesados que sostengan pretensiones contradictorias", interesados entre los cuales puede perfectamente admitirse a la Corporación afectada, sin que nada obste a ello; ahora bien, no obstante ésto, se concedió expresamente a los entes locales la garantía de ser necesariamente oídos en el procedimiento; luego, si lá audiencia expresa se exigió a pesar de la posibilidad de personación, puesto que no ha variado la "ratio legis", debe seguir exigiéndose ahora, visto ya que nada de modo terminante se opone a tal trámite, con cuya supresión se privaría a la Corporación de una garantía que ya tiene sin concederle ninguna nueva. b) Porque la personación tiene carácter voluntario (aunque pudiera ser encuadrada entre "las acciones necesarias para la defensa de sus bienes y derechos" cuyo obligatorio ejercicio prescribe el artículo 370 de la Ley de Régimen local), mientras que la audiencia que configura el Derecho local tiene carácter imprescindible, cuya omisión viciaría de nulidad el procedimiento ( $\sin$ perjuicio de que deba entenderse cumplido el trámite, aunque no se haga uso del derecho durante el plazo concedido para ello); es más, figurando en el mismo cuerpo legal los artículos $\mathbf{7 3 0}$ y $\mathbf{3 7 0}$ de la Ley de Régimen local, debe entenderse que el momento procesal oportuno para cumplir el segundo de ellos es el periodo de audiencia que establece el primero, y no antes, o por lo menos, no antes de modo necesario. c) Porque, si se prescinde del trámite obligatorio de audiencia, resultan equiparados el particular y la Corporación, y parece que ésta debe tener el trato preferente que se le reconoce por el Derecho local, el de que necesariamente se le dé la oportunidad de exponer su punto de vista. d) Porque el trámite obli- 
gado de la audiencia hará más difícil que por negligencia quede la Corporación indefendida, lo que pudiera suceder si por cualquier circunstancia se omite la personación o no se hace en momento suficientemente eficaz.

2) No basta la posible emisión de informe al remitir el expediente: Esta facultad viene reconocida en el artículo 95-3 del nuevo Reglamento, pero la estimamos insuficiente para garantir los intereses de la Corporación, porque: a) No se impone con carácter preceptivo en todos los casos. b) Su ejercicio se concede cuando la Corporación, normalmente, no puede conocer las alegaciones del reclamante, que todavia no han sido formuladas (creemos que la renuncia por el particular al trámite de puesta de manifiesto para alegaciones, incorporando éstas al escrito de interposición del recurso, será excepcional), por lo que mal podrá desvirtuar los razonamientos que fundamenten la reclamación (piénsese, además, que el recurso de reposición puede no haberse utilizado, y que, aunque el reclamante hiciere sus alegaciones en el escrito de interposición, no está previsto que se le.dé a la Corporación traslado u ofrecimiento de vista de las mismas, por lo que el Tribunal se limitará a comunicar que se ha interpuesto la impugnación y a interesar que se remita el expediente de gestión); se informará, pues, defendiendo la legalidad del acto reclamado, pero ignorando el alcance y los motivos que va a tener la impugnación. c) Además de no bastar a la defensa del acto, puede servir para dar armas contra él al reclamante, para mostrarle las apoyaturas de aquélla al menos, ya que nada indica que el citado informe sea reservado al Tribunal. d) $\mathrm{El}$ informe tiene un contenido y alcance mucho más restringido y mucho menos eficaz que una audiencia expresa tras el conocimiento de las alegaciones formuladas, por lo que, si se suprime ésta, se minorarán las garantías de los entes locales.

3) Podría objetarse a la exigencia del trámite de audiencia que ésta no se ofrece a las oficinas de la Hacienda del Estado. Pero ha de tenerse en cuenta : a) Que, bajo la forma de emisión de informe, la audiencia de la oficina estatal de gestión estaba prevista, con carácter imperativo o no según cada caso con- 
creto, por el artículo 69 del Reglamento de 1924, y, como diligencia para mejor proveer, por el artículo 73 del mismo (19). b) Que no existe, que sepamos, en las distintas ramas hacendisticas estatales un precepto que imponga la audiencia de sus respectivos órganos de gestión con la claridad, generalidad. imperatividad y tradicionalidad con que se exige este trámite en lo local. c) Que la representación que unas y otras oficinas de gestión tienen en los Tribunales provinciales es muy distinta, en perjuicio de las de las Corporaciones locales: mientras en reclamaciones sobre asuntos centrales forma parte del Tribunal el jefe de la dependencia a la que corresponde el acto reclamado (art. 17-1), cuando se impugne un acto de la Administración local el jefe de la dependencia que lo formó (lógicamente debiera ser el Interventor, como jefe de los servicios económicos de la Corporación) está sustituído por el Jefe provincial del Servicio de Inspección y Asesoramiento de las Corporacionec Locales (art. 17-2, y art. 792-2 de la Ley de Régimen local); y, aunque es evidente que el Jefe de este Servicio tiene conocimientos más que suficientes e interés bastante para representar a la Corporación en la defensa de la legalidad del acto impugnado, es evidente también que puede no estar tan al corriente como preciso fuere de la mecánica de hecho que ha llevado a él o de consideraciones que sean dignas de ser tenidas en cuenta al momento de fallar, mientras que el jefe de la dependencia central tendrá un conocimiento mucho más directo e inmediato del asunto debatido, y un interés mucho más vinculativo al acto objeto de la reclamación. d) Por añadidura, el Presidente del Tri-

(19) La obligación de pedir los informes que fueren preceptivos alcanza, según el contenido del articulo 69, a la Administración local; po- ello, viniendo este trámite impuesto al margen del Reglamento de 1924, podemos decir que ya con arreglo a él y desde el Real Decreto-ley de 3 de noviembre de 1928 era obligatorio este trámite; en cambio, parece que en el Reglamento de 1924 no se admitian las diligencias para mejor proveer en lo local, puesto que el artículo 73 daba 3 entender que los Tribunales provinciales sólo podian pedir estos informes a alas dependencias de las Delegaciones de Haciendas. En el Reglamento ce $\mathbf{1 9 5 9}$ se admiten estas diligencias en las esferas central y local (art. 106); en cambio, no contiene un precepto semejante al del referido artículo 69 , quizás por la pretensión de ser el ordenamiento exclusivamente regulador de las reclamaciones económico-administrativas. 
bunal es el Delegado de Hacienda. e) Finalmente, ya estaban así las cosas antes del 26 de noviembre de 1959, y ni expresa ni indirectamente se ha dicho ahora que sea suprimido un trámite que con tan marcado carácter necesario se exigía para lo local exclusivamente.

En resumen: Creemos que el Reglamento de 26 de noviembre de 1959 no ha derogado el artículo 730 de la Ley de Régimen local, por lo que está en vigor el trámite de necesaria audiencia a la Corporación interesada en la reclamación económico-administrativa; creemos que es altamente conveniente para las Entidades locales el cumplimiento de este requisito, que estimamos debe ser entendido "ad solemnitatem", del procedimiento en la forma determinada en el Derecho local. Pero, con objeto de aclarar indubitablemente y de modo general cualquier problema de vigencia que pueda presentarse, creemos oportuno que cuanto antes se reitere su subsistencia, aprovechando, si no anterior oportunidad, la coyuntura de la revisión de la legislación local que se está estudiando. 